\title{
[trabalhonecessário
}

\author{
issn: $1808-799 \mathrm{X}$
}

ano 3 número $3-2005$

\section{O novo e precário mundo do trabalho - Reestruturação produtiva e crise do sindicalismo [1]}

Íris Lessa*

Giovanni Alves nos apresenta, nesta obra, um panorama do processo de reestruturação produtiva, ocorrido no Brasil nos anos 80 e que toma impulso na década seguinte, consagrando o toyotismo como um modo de organização da produção cujos princípios e dispositivos estão voltados para adequar a produção de mercadorias às determinações do novo regime de acumulação de capital. O que o autor denomina de "complexo de reestruturação produtiva" tem sua origem na crise dos países capitalistas centrais, ocorrida na década de 70, quando a longa depressão impulsionou a criação de novos métodos de produção e de gestão da força de trabalho. Ao longo do livro, Alves analisa os impactos da chamada acumulação flexível no $A B C$ paulista, indicando o quanto as modificações técnico-organizacionais afetaram objetiva e subjetivamente 0 modo de ser dos trabalhadores, contribuíram para a precarização do trabalho, para o arrefecimento da luta de classes, e por conseqüência para a crise do sindicalismo brasileiro, configurando desta forma, no novo e precário mundo do trabalho.

Fazendo parte da coleção Mundo do Trabalho, organizada por Ricardo Antunes, o livro contém doze capítulos, estruturados em três partes. Na primeira delas, ao longo de três densos capítulos, o autor analisa o aparecimento de uma nova classe operária nos países centrais, bem como a crise do sindicalismo moderno, surgida num contexto de desemprego estrutural e de proliferação da precarização de empregos e salários. Já na segunda parte, ao longo de sete capítulos, a discussão abrange o processo de reestruturação produtiva no Brasil analisando sua constituição através da passagem do "toyotismo restrito" para o "toyotismo sistêmico". Por fim, na terceira e última parte, em 
dois capítulos, o debate é acerca da crise do sindicalismo brasileiro, abordando as estratégias sindicais diante do novo complexo de reestruturação produtiva no país.

Dentre os livros publicados pelo autor estão: "Dimensões da Globalização- Capital e suas contradições"(Praxis,1999), "Trabalho e Mundialização do Capital- A nova Degradação do Trabalho na Era da Globalização"(Praxis, 1999), "Limites do Sindicalismo-Marx, Engels, e a critica da Economia Política"(Praxis, 2003). O autor também é coordenador do NEG (Núcleo de Estudos da Globalização) um campo de pesquisa social e debate interdisciplinar que busca uma compreensão, de orientação critica, das transformações na economia, política, tecnologia, educação, trabalho, cultura e sociedade capitalista. Possuindo as seguintes linhas de pesquisa: Economia Política da Globalização; Trabalho e Globalização; Novas Tecnologias, Ciberespaço e Sociabilidade.

O que é observado em $O$ novo e (precário) mundo do trabalho, publicado pela Boitempo Editorial, é que o toyotismo instaura "uma nova hegemonia do capital, no plano da produção de mercadorias, articulando de modo original, coerção capitalista e consentimento operário" (pg 39). Tendo como princípio a fábrica racionalizada, os operários parcelares (do fordismo) são substituídos por operários polivalentes que, divididos em grupos de trabalho, competem entre equipes e entre si. Com o toyotismo, instituiu-se um maior controle entre trabalhadores e num maior envolvimento do trabalhador no seu ofício: "A Toyota trabalha com grupos de oito trabalhadores(...) Se apenas um deles falha, o grupo perde o aumento, portanto, este último garante a produtividade assumindo o papel que antes era da chefia"(Watanabe, 1993:5, In:Alves, 2000).

Como assinala o autor, fazendo referência a Mészáros, é importante ressaltar que embora mudanças tenham ocorrido na natureza do trabalho industrial, na mudança de condições e interesses dos operários, nos estatuto e salários, as relações estruturais permanecem fundamentalmente as mesmas. Para Giovanni Alves,

"Na pós grande indústria não desaparece a subordinação material do trabalho ao capital. Ao contrário, se restabelece uma nova oposição entre o indivíduo e o processo material, o que implicaria considerar o surgimento de um novo estranhamento. A subsunção real do trabalho ao capital assumiria um novo sentido - é a subordinação formal-intelectual

(ou espiritual)". (pg 71)

Alves nos ajuda a compreender a gênese, o desenvolvimento e avanço do novo complexo de reestruturação produtiva no Brasil, utilizando como estratégia de pesquisa uma análise crítica calcada na contradição capital - trabalho. Tomando por base o materialismo histórico, aponta as mudanças ocorridas no processo produtivo no país, pós-1945, salientando "o sentido histórico do novo complexo de reestruturação produtiva no Brasil, que toma impulso na era neoliberal"(pg103). Devido à trajetória sindical de reivindicação política contra as ofensivas do capital, o autor utilizou como " locus" da pesquisa, o complexo automotivo da região do ABC paulista. Seu objetivo 
ao analisar esta região, que se trata de um dos mais importantes pólos industriais brasileiros, foi perceber como se desenvolveram e se propagaram as novas estratégias da produção capitalista que acarretaram na construção de uma nova subjetividade operária.

Alves, enfatiza como se constituiu a nova subjetividade do trabalho, bem como se deu a formação do novo sindicalismo na região em que nascera a CUT e o PT, com uma história de reivindicações operárias. Ele ressalta que a escolha desse lugar para realizar a pesquisa deveu-se o fato de que foi na indústria automotiva do ABC paulista que o novo complexo de reestruturação produtiva, o qual tornou-se mais intenso nos anos 90, deixa perceber seus efeitos com maior clareza.

O autor tem como centro de suas questões a classe operária vinculada a uma das principais indústrias automobilística do país: os metalúrgicos. Ela possui uma das maiores organizações sindicais do Brasil: Sindicato dos Metalúrgicos do ABC paulista. O ator político de sua obra é o sindicato. É através dele que podemos verificar o quanto o processo de reestruturação produtiva debilitou a estrutura da classe operária. $O$ sindicato que até os anos 80 , combatia intensamente a manipulação do capital, sendo muitas vezes vitorioso nesta luta - tanto que "a oposição dos sindicatos aos CCQ's acabou por esvaziar muitas das iniciativas empresariais"(pg127) - se tornou, a partir dos anos 90 , menos ofensivo ao avanço do capital:

"No decorrer dos anos 90, a luta operária metalúrgica no ABC concentrou-se em buscar uma intervenção propositiva dos trabalhadores no processo decisório da reestruturação produtiva que ocorre no interior das empresas. Diante da ofensiva do capital na produção, o sindicato tende a exigir dos capitalistas, cada vez mais, os direitos de informação e consulta prévia dos planos de inovação, formas de participação e negociação, capazes de influenciar, no sentido propositivo, as transformações técnico- organizacionais, voltando-se para a garantia de emprego, salário e condições de trabalho, que podem ser alcançadas, por exemplo, segundo elas, pela melhoria da produtividade. Só que a produtividade e a competitividade devem ser alcançadas, segundo o sindicalismo propositivo, não pelos recursos "espúrios", de cortes da força de trabalho, mas pelos da nova valorização do trabalhador, visto como parceiros do capital". (pg

As mudanças no processo produtivo introduzidas pelo novo complexo de reestruturação produtiva (a terceirização, just in time/ kaban, implementação de novas tecnologias, relocalização geográfica de diversas empresas) repercutiram em demissões em massa, na modificação da estrutura dos trabalhadores industriais, ocasionando uma fragmentação da classe operária. Este fato é intrínseco à crise do sindicalismo moderno: há uma crise dos intelectuais orgânicos da classe, sindicatos e partidos socialistas, capazes de desenvolver a consciência necessária de classe. (pg 65)

Assim, o autor explica que a grande perda sindical adveio com a inversão de seus valores defendidos: os sindicatos deixaram de ser um lugar de reivindicações 
políticas contra o modelo de acumulação capitalista e em prol do sentido de classe, para se adaptar ao capital e suas estratégias:

“(...)o abandono de estratégias sindicais de classe e da crítica do controle do capital na produção, assumindo, ao contrário, estratégias sindicais próativas à lógica do capital, compatível com o espírito do toyotismo, que incentiva o operário a pensar "pró- ativamente", a encontrar soluções antes que os problemas aconteçam". (pg 83)

É, nesse quadro, que os sindicatos neocorporativistas surgem: eles são frutos de mudanças políticas e ideológicas ocorridas nos sindicatos de classe - o que repercute, segundo Giovanni Alves, em políticas sindicais de colaboração com 0 capital .

"O cerne essencial da crise do sindicalismo é a sua incapacidade( ou limitação estrutural) de preservar o seu poder de resistência de classe à sanha da valorização, diante da nova ofensiva do capital na produção e do novo (e precário) mundo do trabalho."(pg85)

As denominações utilizadas pelo autor "toyotismo restrito" e "toyotismo sistêmico" (cap. V e IX) nos ajudam a compreender que os anos 80 significou uma espécie de "fase inicial" para as alterações mais profundas que ocorreriam no processo produtivo brasileiro nos anos 90, quando se dá implantação do toyotismo sistêmico, impulsionado pelo governo neoliberal. Sendo assim, a passagem do toyotismo restrito para o toyotismo sistêmico significa para Alves "a constituição lenta (e contraditória) de uma nova hegemonia do capital na produção e o desenvolvimento de um novo (e precário) mundo do trabalho no Brasil".

Percebemos, nesta obra, que no caso brasileiro, o processo de introdução e da passagem do toyotismo restrito para o toyotismo sistêmico, com a efetiva adoção de novas formas de organizar a produção como o just-in time e o kaban, significou uma mudança radical na estrutura da classe trabalhadora:

"A crise política (e ideológica) das estratégias de classe criou as condições

"subjetivas" para a nova hegemonia do capital na produção. É uma variável política decisiva se considerarmos que, o que se procura constituir com o novo complexo de reestruturação produtiva, caracterizado pelo toyotismo sistêmico, é uma captura da subjetividade operária pela lógica do capital, um novo consentimento operário( ativo e propositivo), em especial no plano de suas organizações sindicais, compatível com as necessidades da produção capitalista na pós grande indústria( o que implica debilitar posturas classistas de cariz socialista, avessas à parceria do capital na produção)".(pg 190)

O processo produtivo brasileiro, a partir dos anos 90, se tornou cada vez mais descentralizado (terceirização e relocalização industrial), com uma tendência ao "trabalho flexível", ou seja, trabalhadores com menor vínculo empregatício com a empresa. Tudo isso, como nos indica Alves, corrobora para perda da solidariedade entre os trabalhadores. Com o novo complexo de reestruturação produtiva, o trabalhador se tornou cada vez mais individualizado: "o operário polivalente aparece cada vez mais como um servidor de um sistema de máquinas"(pg 71). 
Mais precisamente a partir de 1993, no Brasil, o mundo do trabalho começa a sentir os fortes impactos desta nova etapa de acumulação, quando na indústria automobilística, o aumento da produtividade se deu com a diminuição dos postos de trabalho nas montadoras. Com o Plano Real em 1994, ocorreu em nosso país, um impulso para a adoção da automação microeletrônica nos principais pólos industriais. Ademais, o processo de terceirização, bem como a flexibilização das leis trabalhistas, como a Lei do Trabalho Temporário, aprovada no Brasil em 1998, significou e, ainda significa, a consolidação da flexibilidade da produção e do trabalho, portanto, a instauração de uma nova estrutura de organização do trabalho industrial.

Em suma, em seu livro, Giovanni Alves faz um estudo sobre a repercussão que o novo padrão de acumulação, implementado na indústria automobilística, causou aos trabalhadores. $\mathrm{O}$ autor salienta que $\mathrm{o}$ ideal do toyotismo se caracteriza pela captura da subjetividade do trabalho pelos valores capitalistas. Isso tende a dissolver as perspectivas classistas da prática operária e sindical, características estas, do novo e precário mundo do trabalho. Por diversas vezes, o autor ratifica que a vigência de práticas neocorporativas de caráter propositivo pelos sindicatos é sinônimo de um sindicalismo cada vez mais fechado em si mesmo e incapaz de articular movimentos sociais classistas mais amplos, destacando a incapacidade dos sindicatos de resistirem as ofensivas da chamada acumulação flexível.

Enfim, toda esta discussão proposta pelo autor, nos estimula a refletir em que medida as modificações ocorridas no processo produtivo, dinamizado pela mundialização do capital pode modificar e fragmentar a solidariedade da classe trabalhadora. E, principalmente nos ajuda a refletir se, de fato, a nova base técnica da produção tem a capacidade de determinar o caráter do movimentos sindicais. Seria este um processo irreversível? Venceram os homens-de-negócio com suas tecnologias de produção e gestão da força de trabalho? Estaria findada a luta?

[1] Giovanni Alves (São Paulo: Boitempo Editorial, 2000)

$\left.{ }^{*}{ }^{\star}\right]$ Aluna do $6^{\circ}$ período de Ciências Sociais. Bolsista do PIBIC-UFF/CNPq 